Article

\title{
Effects of Thawing and Frying Methods on the Formation of Acrylamide and Polycyclic Aromatic Hydrocarbons in Chicken Meat
}

\author{
Jong-Sun Lee ${ }^{1}$, Ji-Won Han ${ }^{1}$, Munyhung Jung ${ }^{2}$, Kwang-Won Lee ${ }^{3}$ and Myung-Sub Chung ${ }^{1, * \mathbb{D}}$ \\ 1 Department of Food Science and Technology, Chung-Ang University, 4726 Seodongdae-Ro, Daedeok-Myeon, \\ Anseong-Si 17546, Korea; gpqls3873@naver.com (J.-S.L.); w_w3333@naver.com (J.-W.H.) \\ 2 Department of Food and Biotechnology, Graduate School, Woosuk University, Samnye-eup, \\ Wanju-gun 55338, Korea; munjung@woosuk.ac.kr \\ 3 Department of Biotechnology, College of Life Sciences and Biotechnology, Korea University, Anam-Dong, \\ Sungbuk-Gu, Seoul 02841, Korea; kwangwon@korea.ac.kr \\ * Correspondence: chungms@cau.ac.kr; Tel.: +82-31-670-3272
}

Received: 30 March 2020; Accepted: 23 April 2020; Published: 4 May 2020

\begin{abstract}
Air frying is commonly used as a substitute for deep-fat frying. However, few studies have examined the effect of air frying on the formation of potential carcinogens in foodstuffs. This study aimed to investigate the formation of acrylamide and four types of polycyclic aromatic hydrocarbons (PAHs) in air-fried and deep-fat-fried chicken breasts, thighs, and wings thawed using different methods, i.e., by using a microwave or a refrigerator, or by water immersion. The acrylamide and PAHs were analyzed by high-performance liquid chromatography-tandem mass spectrometry (HPLC-MS/MS) and gas chromatography-mass spectrometry (GC-MS), respectively. Deep-fat-fried chicken meat had higher acrylamide (n.d.-6.19 $\mu \mathrm{g} / \mathrm{kg}$ ) and total PAH $(2.64-3.17 \mu \mathrm{g} / \mathrm{kg}$ ) air-fried chicken meat (n.d. $-3.49 \mu \mathrm{g} / \mathrm{kg}$ and $1.96-2.71 \mu \mathrm{g} / \mathrm{kg}$ ). However, the thawing method did not significantly affect the formation of either acrylamide or PAHs. No significant differences in the acrylamide contents were observed among the chicken meat parts, however, the highest PAH contents were found in chicken wings. Thus, the results demonstrated that air frying could reduce the formation of acrylamide and PAHs in chicken meat in comparison with deep-fat frying.
\end{abstract}

Keywords: chicken; air frying; deep-fat frying; acrylamide; polycyclic aromatic hydrocarbons

\section{Introduction}

Although meat consumption has increased steadily in recent years, the consumption of low-fat, low-calorie, and high-protein chicken has grown significantly [1]. The number of chicken franchise stores in Korea has increased from 9000 in 2002 to 24,602 in 2018 [2]. Additionally, the domestic consumption of chicken has continued to grow from $7.5 \mathrm{~kg}$ per person per year in 2005 to $14.2 \mathrm{~kg}$ per person per year in 2018 [3]. The consumption of chicken in the USA has also increased from $39.2 \mathrm{~kg}$ per person per year in 2005 to $42.6 \mathrm{~kg}$ per person per year in 2018 [4]. In the European Union, the production of chicken has increased from 8169 billion tons per year in 2005 to 12,260 billion tons per year in 2018 [5]. Furthermore, the most frequently consumed meat cooked at high temperatures is fried chicken [6].

Generally, frying involves more rapid heat transfer in comparison with other cooking methods. The lowest temperature employed for frying is $140{ }^{\circ} \mathrm{C}$, although fried food is typically cooked at temperatures between $175{ }^{\circ} \mathrm{C}$ and $195{ }^{\circ} \mathrm{C}$ [7]. High temperatures promote dehydration of the crust, oil intake, and the chemical reactions of various food constituents such as the denaturation of proteins and the caramelization of carbohydrates [8-10]. Moreover, the compounds produced via the 
Maillard reaction during frying enhance the aroma, color, crust, and texture of the food but reduce its nutritional quality [11,12].

Many epidemiological studies have indicated that a high consumption of processed meats may increase the risk of cancer (e.g., breast, prostate, colorectal, ureter, and pancreatic) in humans because the high cooking temperatures employed in their production can result in high levels of carcinogenic compounds, such as acrylamide and polycyclic aromatic hydrocarbons (PAHs) [13-15]. Acrylamide, which is classified as a probable carcinogen to humans (Group 2A) by the International Agency for Research on Cancer (IARC) [16], is also produced during the frying of chicken [14]. Additionally, based on previous studies regarding the carcinogenicity, epidemiology, and mutagenicity of the PAH benzo[a]pyrene $(\mathrm{B}(\mathrm{a}) \mathrm{P})$, it was categorized by the IARC as a Group 1 carcinogen, indicating that it is carcinogenic to humans [17]. Furthermore, PAHs are known to be endocrine disorder substances, which have long residual terms and exhibit high toxicities as carcinogens [18]. Formerly, the European Commission (EC) regulations required the use of $\mathrm{B}(\mathrm{a}) \mathrm{P}$ as a marker for the content of carcinogenic PAHs in foods [19]. However, as B(a)P was not always found in foods containing PAHs, in 2008, a group of four PAHs (PAH4) and a group of eight PAHs (PAH8) were proposed as better indicators based on data relating to occurrence and toxicity [20]. However, PAH8 measurements provided no additional advantage over PAH4 measurements. Based on comments from the European Food Safety Authority, in 2011, the EC expanded the scope of their regulations to include other food types and to add restrictions on PAH4 levels [21].

As the formation of carcinogenic compounds, such as acrylamide and PAHs, in chicken meat poses a significant risk to human health, studies are required to determine alternative cooking methods that produce healthier products without compromising the texture, flavor, taste attributes, and appearance [22-24]. For example, some previous studies have investigated limiting the formation of carcinogenic compounds through the use of precooking methods, such as microwave prethawing, predrying, and low-pressure frying [25-27]. An additional means to reduce the formation of carcinogenic compounds is the use of a different cooking method. For example, air frying is commonly used as a substitute for deep-fat frying. This method produces fried food using only a small quantity of fat through oil droplets spread in a hot air stream. Direct contact between the dispersion of oil droplets in hot air and the product inside a closed chamber provides constant heat transfer rates between the air and the food being fried. Thus, this technology permits a reduction of $\sim 90 \%$ in the fat content of fried products [24]. Moreover, a 77\% reduction in the acrylamide content of air-fried French fries has also been reported ( $30 \mu \mathrm{g} / \mathrm{kg}$ for air frying and $132 \mu \mathrm{g} / \mathrm{kg}$ for deep-fat frying [28]). Importantly, the air-fried food was crispy on the outside and moist on the inside, and the sensory properties of the final product were similar to those obtained after deep-fat frying. Furthermore, the smell of the food during cooking was less intense in comparison with other frying methods. For this reason, air fryer purchases have risen from $2 \%$ in 2014 to $38 \%$ in 2018 [29].

However, despite the number of studies conducted to evaluate the effect of hazardous compound formation in fried foods, few studies have examined the effect of air frying on the formation of acrylamide and PAHs in foodstuffs. Thus, we herein investigate the formation of acrylamide and four types of PAHs in chicken breasts, thighs, and wings fried by air frying and deep-fat frying after thawing using a microwave or a refrigerator, or by water immersion. Higher acrylamide and PAH contents were found in deep-fat-fried chicken meat than in air-fried chicken meat, but the thawing method did not significantly affect the formation of either acrylamide or PAHs. Thus, air frying is a promising method for reducing the formation of potentially hazardous compounds in chicken.

\section{Materials and Methods}

\subsection{Raw Materials}

Frozen skinless chicken breasts as well as thighs and wings with skin (Harim Co. Ltd., Iksan-si, South Korea) were purchased from a local food market (Jeonju, South Korea). Soybean oil (CJ 
CheilJedang, Seoul, South Korea) was purchased from a local food market and used for frying the chicken samples.

\subsection{Chemicals}

Acrylamide ( $>99 \%)$ and ${ }^{13} \mathrm{C}_{3}$-acrylamide ( $>99 \%$ ) were supplied by Cambridge Isotope Laboratories (Andover, MA, USA). Formic acid ( $>99 \%$ ) was purchased from Sigma-Aldrich (St. Louis, MO, USA) and methanol was supplied by J.T. Baker (Phillipsburg, NJ, USA).

Strata-X (200 mg, $6 \mathrm{~mL})$ and Bond Elut AccuCAT (200 mg, $3 \mathrm{~mL})$ solid-phase extraction (SPE) cartridges were purchased from Phenomenex (Torrance, CA, USA) and Agilent Technologies (Santa Clara, CA, USA), respectively. Polyvinylidene fluoride (PVDF) syringe filters were purchased from Futecs Co. (Daejeon, South Korea).

Benzo(a)anthracene $(\mathrm{B}(\mathrm{a}) \mathrm{A})$, benzo $(\mathrm{b})$ fluoranthene $(\mathrm{B}(\mathrm{b}) \mathrm{F})$, chrysene $(\mathrm{CRY})$, and $\mathrm{B}(\mathrm{a}) \mathrm{P}$ standards as well as benzo(a)pyrene-d12 (B(a)P-d12) and chrysene-d12 (CRY-d12) internal standards (I.S.) were purchased from Supelco (Bellefonte, PA, USA). Organic solvents, including $n$-hexane, ethanol, and dichloromethane, were purchased from Burdick \& Jackson (Muskegon, MI, USA). Potassium hydroxide $(>85 \%)$ for alkali saponification was purchased from Showa Denko (Tokyo, Japan). Sodium sulfate anhydrous ( $>99 \%$ ) for dehydration from Yakuri Pure Chemicals (Kyoto, Japan) and filter paper from Whatman (Maidstone, UK) were used for the dehydration process. Sep-Pak cartridges Agilent Technologies (Santa Clara, CA, USA) were used for SPE. Polytetrafluoroethylene (PTFE) membrane syringe filters from Whatman (Maidstone, UK) and $1 \mathrm{~mL}$ syringes from KOREAVACCINE (Ansan-Si, South Korea) were used for the filtration process.

All chemicals used for the determination of acrylamide and the PAHs were of analytical or high-performance liquid chromatography (HPLC) analytical grade.

\subsection{Thawing Procedures}

Chicken thigh, wing, and breast samples of approximately $100 \mathrm{~g}$ were employed for the thawing experiments. The frozen chicken samples were subjected to three different home-based thawing practices prior to frying. In accordance with the sanitation standard operating manual [30], the chicken was packed in a low-density polyethylene plastic bag (Cleanwrap, South Korea) for thawing by immersion in water and for refrigeration. Microwave thawing was conducted in a polypropylene microwave-specific container (LocknLock, South Korea). Specifically, the thawing practices used in this study were as follows: (i) Thawing in a microwave (KR-M201BWB; Winia Daewoo, South Korea) at $310 \mathrm{~W}$ for $3 \mathrm{~min}$; (ii) thawing in a refrigerator (GC-114HCMP; LG Electronics, South Korea) at $4{ }^{\circ} \mathrm{C}$ for $24 \mathrm{~h}$; and (iii) thawing by immersion in distilled water at $20^{\circ} \mathrm{C}$ for $1 \mathrm{~h}$ (changing the water after $30 \mathrm{~min}$ ). These thawing practices are suggested by the United States Department of Agriculture (USDA) as safe defrosting methods [31]. Frying was performed immediately after thawing to prevent contamination [30].

\subsection{Frying Procedures}

Deep-fat frying was performed in a domestic electric fryer (model DK-201; Delki, South Korea) with an adjustable temperature up to $190^{\circ} \mathrm{C}$, a $6 \mathrm{~L}$ capacity, and a nominal power of $2000 \mathrm{~W}$. The temperature was controlled using a digital thermometer. Hot air frying was conducted using an HD9220 Air Fryer (Royal Philips Electronics N.V., Amsterdam, The Netherlands) with an adjustable temperature up to $200{ }^{\circ} \mathrm{C}$, a $2.2 \mathrm{~L}$ capacity, and a nominal power of $1425 \mathrm{~W}$. Approximately $100 \mathrm{~g}$ of each sample of the thawed chicken thighs, wings, and breasts were fried at the same time when the temperatures of both fryers reached $180^{\circ} \mathrm{C}$. Deep-fat frying was performed for $10 \mathrm{~min}$ using an oil volume of $3.6 \mathrm{~L}$, and the oil was changed thrice for triplicate experiments. Air frying was performed for $35 \mathrm{~min}$, and the samples were flipped once after $20 \mathrm{~min}$ without oil spray. 


\subsection{Sample Preparation}

All fried chicken parts were cooled to room temperature (approximately $20^{\circ} \mathrm{C}$ ) after frying and the chicken bone was removed. The deboned skinless chicken breasts and the thighs and wings with skin were homogenized using a Ninja blender (Hai Xin Technology Co. Ltd., Shenzhen, China) for $2 \mathrm{~min}$, and the homogenized samples were stored at $4{ }^{\circ} \mathrm{C}$ prior to analysis.

\subsection{Determination of Acrylamide Content}

The analytical method employed for acrylamide determination was based on The Ministry of Food and Drug Safety method with minor modifications [32]. Specifically, each homogenized chicken sample $(1 \mathrm{~g})$ was added to water $(9 \mathrm{~mL})$ and ${ }^{13} \mathrm{C}_{3}$ acrylamide $(1 \mathrm{~mL}, 200 \mathrm{ng} / \mathrm{mL})$ in a $50 \mathrm{~mL}$ tube. The tube was shaken at $250 \mathrm{rpm}$ for $20 \mathrm{~min}$, centrifuged (COMBI-514R; Hanil Scientific Inc., Gimpo-si, South Korea) at $3500 \mathrm{rpm}$ for $5 \mathrm{~min}$, and filtered through a $0.45 \mu \mathrm{m}$ PVDF syringe filter. A Strata-X SPE column was conditioned with methanol $(3.5 \mathrm{~mL})$ followed by water $(3.5 \mathrm{~mL})$. An aliquot of the sample $(1.5 \mathrm{~mL})$ was introduced onto the cartridge followed by water $(0.5 \mathrm{~mL})$, and the eluent was discarded. Then, further water $(1.5 \mathrm{~mL})$ was passed through the column and the eluent was collected. A Bond Elut AccuCAT SPE column was conditioned using methanol $(2.5 \mathrm{~mL})$ followed by water $(2.5 \mathrm{~mL})$. Finally, after passing an aliquot $(0.5 \mathrm{~mL})$ of the eluate collected from the Strata-X SPE column through the preconditioned Bond Elut AccuCAT SPE column, an aliquot $(1 \mathrm{~mL})$ of the eluate from the Strata-X column was introduced onto the Bond Elut AccuCAT SPE column and was collected in $2 \mathrm{~mL}$ vials.

High-performance liquid chromatography-tandem mass spectrometry (HPLC-MS/MS) was performed using a Shimadzu 30A HPLC system coupled to a Shimadzu MS8040 MS/MS system (Shimadzu, Kyoto, Japan). The HPLC-MS/MS analytical conditions are outlined in Table 1. The multiple reaction monitoring (MRM) transitions for the quantitation of acrylamide and ${ }^{13} \mathrm{C}_{3}$ acrylamide (internal standard) were $m / z 72>55$ and $m / z 75>58$, respectively.

Table 1. Analytical conditions employed for high-performance liquid chromatography-tandem mass spectrometry (HPLC-MS/MS) analysis of acrylamide contents in chicken samples.

\begin{tabular}{cc}
\hline Item & Conditions \\
\hline HPLC instrument & Shimadzu 30A \\
Column & Kinetex polar C18 $(150 \mathrm{~mm} \times 2.1 \mathrm{~mm}$ i.d., $2.6 \mu \mathrm{m}$ particle size, Phenomenex $)$ \\
Flow rate & $0.3 \mathrm{~mL} / \mathrm{min}$ \\
Oven temperature & $26{ }^{\circ} \mathrm{C}$ \\
Injection volume & $20 \mu \mathrm{L}$ \\
Mobile phases & $0.5 \%$ methanol in distilled water and $0.1 \%$ acetic acid \\
MS/MS instrument & Shimadzu MS8040 \\
Ionization mode & Electrospray ionization, $5000 \mathrm{~V}$, positive mode, \\
Detection mode & MRM mode \\
Desolvation gas, collision gas & $\mathrm{N}_{2}$ \\
\hline & MRM: multiple reaction monitoring.
\end{tabular}

A calibration curve for acrylamide was prepared in the range of $0.5-200 \mu \mathrm{g} / \mathrm{L}$. The correlation coefficient was 0.999. Based on the calibration curve parameters, the limit of detection (LOD) and the limit of quantification (LOQ) were calculated as $0.186 \mu \mathrm{g} / \mathrm{kg}$ and $0.562 \mu \mathrm{g} / \mathrm{kg}$, respectively.

\subsection{Determination of PAH Content}

The PAH content was determined using the method of Lee et al. [33] with modifications. Specifically, each homogenized chicken sample $(1 \mathrm{~g})$ was placed in a flat-bottomed $300 \mathrm{~mL}$ flask, and then spiked with an internal standard mixture $(1 \mathrm{~mL}, 100 \mu \mathrm{g} / \mathrm{kg}$ of CRY-d12 and B(a)P-d12). The combined $n$-hexane phase was washed with distilled water $(3 \times 50 \mathrm{~mL})$, dried over $\mathrm{Na}_{2} \mathrm{SO}_{4}$, and concentrated using a rotary evaporator (N-1110, EYELA, Seoul, South Korea) at $37^{\circ} \mathrm{C}$ to give a final volume of $2 \mathrm{~mL}$. The samples were then eluted using a Sep-Pak silica cartridge, which was 
activated with hexane $(20 \mathrm{~mL})$. The resulting solution was concentrated to dryness under $\mathrm{N}_{2}$ gas at $40{ }^{\circ} \mathrm{C}$, and the residue was redissolved in dichloromethane $(1 \mathrm{~mL})$. This solution was passed through a $0.45 \mu \mathrm{m}$ PTFE membrane filter and transferred into a $2 \mathrm{~mL}$ amber screw cap vial. Finally, the PAH contents were analyzed using gas chromatography-mass spectrometry (GC-MS) following a slightly modified standard procedure. GC-MS analyses were performed using an Agilent Technologies 7890A gas chromatograph coupled to an Agilent Technologies 5977B mass spectrometer (Agilent Technologies, Santa Clara, CA, USA). The GC-MS conditions used to analyze the PAH contents are outlined in Table 2. The selected ions employed for the four PAHs and the standards in selected ion monitoring (SIM) mode were as follows: B(a)A ( $m / z$ 228, 226, 229), B(b)F $(m / z$ 252, 250, 253), CRY $(m / z$ 228, 226, 229), B(a)P $(\mathrm{m} / \mathrm{z}$ 252, 250, 253), B(a)P-d12 $(\mathrm{m} / \mathrm{z} \mathbf{2 6 4}, 263,265)$, and CRY-d12 $(\mathrm{m} / \mathrm{z} \mathbf{2 4 0}, 236,241)$. The values in bold indicate the quantification ions.

Table 2. Gas chromatography-mass spectrometry (GC-MS) conditions for analysis of the four polycyclic aromatic hydrocarbons (PAHs) in chicken samples.

\begin{tabular}{cc}
\hline Item & Conditions \\
\hline GC instrument & Agilent Technologies 7890A \\
Column & HP-5MS UI \\
& $(30 \mathrm{~m} \times 250 \mu \mathrm{m}$ i.d., $0.25 \mu \mathrm{m}$ film thickness $)$ \\
Column oven temperature & $80^{\circ} \mathrm{C}(1 \mathrm{~min}) \rightarrow 4^{\circ} \mathrm{C} / \mathrm{min}, 220^{\circ} \mathrm{C}$ \\
Post run & $\rightarrow 20^{\circ} \mathrm{C} / \mathrm{min}, 280^{\circ} \mathrm{C}(10 \mathrm{~min})$ \\
Flow rate & $310^{\circ} \mathrm{C}, 10 \mathrm{~min}$ \\
Injection mode & $1.5 \mathrm{~mL} / \mathrm{min}$, helium \\
Injection volume & Splitless mode \\
Injection temperature & $1 \mu \mathrm{L}$ \\
MS instrument & $320^{\circ} \mathrm{C}$ \\
Fragmentation mode & Agilent Technologies $5977 \mathrm{~B}$ \\
Detection mode & Electron impact at $70 \mathrm{eV}$ \\
& SIM mode \\
\hline
\end{tabular}

SIM: selected ion monitoring.

\subsection{Statistical Analysis}

The experimental data were evaluated using the analysis of variance (ANOVA). Using the SPSS software program (IBM Inc., Chicago, IL, USA), significant differences $(p<0.05)$ among the means were determined from triplicate analysis using Duncan's multiple range test. The differences between the means of the two frying methods were estimated using the $t$-test for independent samples. Values were considered significant at $p<0.05$.

\section{Results and Discussion}

\subsection{Acrylamide Contents of Air-Fried and Deep-Fat-Fried Chicken Meat Parts}

Figure 1 depicts the retention times of the acrylamide standard and internal standard in the HPLC-MS/MS chromatograms of a typical chicken meat sample. The acrylamide contents of the air-fried and deep-fat-fried chicken breast, thigh, and wing samples after thawing in a microwave, in a refrigerator, and by immersion in water are presented in Table 3 . The effects of the frying method on acrylamide formation were examined using the same thawing method and the same chicken meat part.

The acrylamide levels of the deep-fat-fried chicken meats ranged from n.d. (not detected) to $6.19 \mu \mathrm{g} / \mathrm{kg}$, whereas those of the air-fried chicken meats ranged from n.d. to $3.49 \mu \mathrm{g} / \mathrm{kg}$. Overall, the deep-fat-fried samples contained significantly higher acrylamide levels than the air-fried samples, with the exception of the thigh and wing parts thawed in a refrigerator. For this study, deep-fat frying was performed using soybean oil for $10 \mathrm{~min}$, whereas air frying was conducted without an oil spray for $25 \mathrm{~min}$. Despite the longer frying time, lower acrylamide levels were observed in the air-fried chicken meat samples. It has been proposed that acrylamide is formed from acrolein, which originates 
from lipid degradation (i.e., oxidized fatty acids or glycerol) [11]. Acrolein is produced when lipids are heated at high temperatures [34]. More specifically, acrolein forms acrylic acid through oxidation and can react to generate an intermediate acrylic radical. Both species can yield acrylamide in the presence of a nitrogen source and under favorable reaction conditions [35]. Similarly, the level of acrylamide formation increased during the heating of potatoes when oil was added [36].

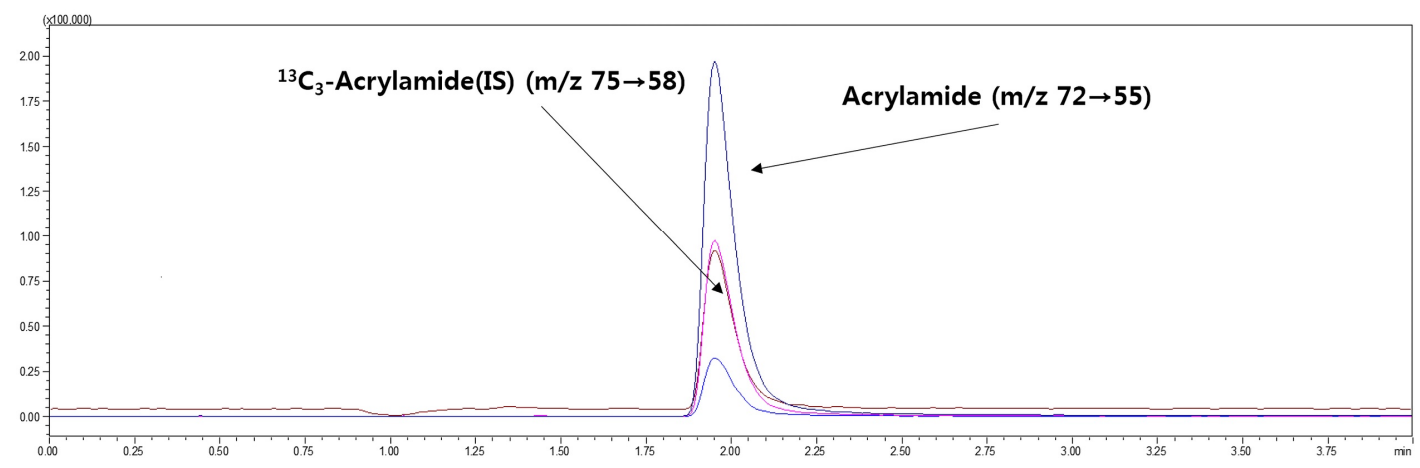

Figure 1. Typical high-performance liquid chromatography-tandem mass spectrometry (HPLC-MS/MS) chromatograms for the acrylamide standard $(100 \mu \mathrm{g} / \mathrm{kg})$ and the internal standard $(20 \mu \mathrm{g} / \mathrm{kg})$ in deep-fat-fried chicken wing samples after thawing by water immersion.

Table 3. Acrylamide levels of air-fried and deep-fat-fried chicken meats thawed using a microwave, a refrigerator, and water immersion.

\begin{tabular}{|c|c|c|c|}
\hline Frying Method & Thawing Method & Chicken Part & Acrylamide Levels $(\mu \mathrm{g} / \mathrm{kg})^{1}$ \\
\hline \multirow{9}{*}{ Air frying } & \multirow{3}{*}{ Microwave } & Breasts & n.d. \\
\hline & & Thighs & n.d. \\
\hline & & Wings & $3.49 \pm 0.54^{\mathrm{BXa}}$ \\
\hline & \multirow{3}{*}{ Refrigerator } & Breasts & n.d. \\
\hline & & Thighs & $2.23 \pm 1.50^{\mathrm{AXa}}$ \\
\hline & & Wings & $2.84 \pm 0.68^{\mathrm{AXa}}$ \\
\hline & \multirow{3}{*}{ Water immersion } & Breasts & n.d. \\
\hline & & Thighs & $2.10 \pm 0.55^{\mathrm{BXa}}$ \\
\hline & & Wings & $2.74 \pm 0.20^{\mathrm{BXa}}$ \\
\hline \multirow{9}{*}{ Deep-fat frying } & \multirow{3}{*}{ Microwave } & Breasts & n.d. \\
\hline & & Thighs & $2.85 \pm 0.47^{\mathrm{AYb}}$ \\
\hline & & Wings & $4.91 \pm 0.38^{\mathrm{AXa}}$ \\
\hline & \multirow{3}{*}{ Refrigerator } & Breasts & $2.52 \pm 1.29^{\mathrm{AXb}}$ \\
\hline & & Thighs & $3.14 \pm 0.95^{\mathrm{AXYab}}$ \\
\hline & & Wings & $4.91 \pm 1.87^{\mathrm{AXa}}$ \\
\hline & \multirow{3}{*}{ Water immersion } & Breasts & $3.22 \pm 0.82^{\mathrm{AXb}}$ \\
\hline & & Thighs & $4.62 \pm 0.72^{\mathrm{AXb}}$ \\
\hline & & Wings & $6.19 \pm 1.11^{\mathrm{AXa}}$ \\
\hline
\end{tabular}

1: Each value represents the average of three independent repetitions \pm standard deviation. ${ }^{\mathrm{A}, \mathrm{B}}$ indicate statistically significant differences $(p<0.05)$ between the acrylamide levels of the same thawing methods and the same chicken meat parts where the frying method was varied. ${ }^{X, Y}$ indicate statistically significant differences $(p<0.05)$ among the acrylamide levels of the same chicken meat parts and the same frying methods where the thawing method was varied. ${ }^{a}$ b indicate statistically significant differences $(p<0.05)$ among the acrylamide levels of the chicken meat parts where the same frying methods and same thawing methods were used. n.d. (not detected) indicates that the level was below the limit of detection (LOD).

\subsection{Effect of Thawing Method on Acrylamide Formation}

The effect of the thawing method (i.e., microwave, refrigerator, or water immersion) on the formation of acrylamide was examined using the same frying method and the same chicken meat part. No significant differences were observed $(p>0.05)$, except for the deep-fat-fried thigh meat thawed using a microwave. In this context, Erdoğdu et al. [37] reported that microwave precooking is an 
efficient way to decrease acrylamide formation in French fries by down-regulating the frying time and temperature. Additionally, Demirok and Kolsarıc1 [14] used microwave pretreatment to reduce the levels of acrylamide from 95.15 to $94.13 \mu \mathrm{g} / \mathrm{kg}$ for coated chicken thighs and from 90.47 to $84.38 \mu \mathrm{g} / \mathrm{kg}$ for coated chicken wings.

\subsection{Acrylamide Formation in Different Chicken Meat Parts}

The formation of acrylamide in the chicken breasts, thighs, and wings thawed and fried using the same methods was examined. In general, independent of the frying method employed, the chicken wings contained the highest acrylamide contents, followed by the chicken thighs and the breast meat. No significant differences $(p>0.05)$ were observed among the air-fried chicken meat parts, whereas the deep-fat-fried chicken wings contained significantly higher acrylamide contents than the breast and thigh samples $(p<0.05)$. These results may be due to the different fat contents in the chicken meat parts. The EC established a recommended permitted value of $1000 \mu \mathrm{g} / \mathrm{kg}$ for residual acrylamide in potato crisps [38]; however, in our study, this value was not exceeded for any sample. Specifically, the acrylamide levels of the fried chicken samples produced herein were in the range of n.d. $-3.22 \mu \mathrm{g} / \mathrm{kg}$ for the breast samples, n.d. $-4.62 \mu \mathrm{g} / \mathrm{kg}$ for the thigh samples, and $2.74-6.19 \mu \mathrm{g} / \mathrm{kg}$ for the wing samples, which are extremely low levels. These results may be due to the use of fresh soybean oil in each frying experiment.

\subsection{PAH Contents in Air-Fried and Deep-Fat-Fried Chicken Meat Samples}

Figure 2 illustrates the GC-MS total ion chromatograms of a standard mixture of the four PAHs (PAH4, $10 \mu \mathrm{g} / \mathrm{kg}$ ) and the internal standards $(10 \mu \mathrm{g} / \mathrm{kg})$. The PAH levels of the air-fried and deep-fat-fried chicken breast, thigh, and wing samples after thawing in a microwave, in a refrigerator, or by immersion in water are presented in Table 4 . The results obtained for the two frying methods were compared for the same meat parts and thawing methods.

The sums of the four PAH levels for the deep-fat-fried chicken meat samples ranged from 2.60 to $3.17 \mu \mathrm{g} / \mathrm{kg}$, whereas for the air-fried samples, these values ranged from 1.96 to $2.71 \mu \mathrm{g} / \mathrm{kg}$. The deep-fat-fried chicken meats exhibited significantly higher $(p<0.05)$ total PAH levels than the air-fried chicken meats. Methyl linoleate is known to produce the highest levels of PAHs, followed by methyl oleate and methyl stearate, and it has been concluded that a greater extent of PAH formation occurs as the degree of unsaturation of the added lipids increases [39]. This behavior was attributed to unsaturated fatty acids being more prone to oxidation during heating [40]. It has previously been discussed that unsaturated fatty acids form cyclic monomers or dimers through polymerization [41]. According to Kostik et al. [42], the unsaturated fatty acid composition of soybean oil consists of oleic acid $(28.5 \%, \mathrm{w} / \mathrm{w})$, linoleic acid $(49.5 \%)$, and linolenic acid $(8 \%)$. Additionally, soybean oil should be susceptible to PAH formation because linoleic acid and linolenic acid are likely precursors of such lipid breakdown products [39]. Therefore, our results indicated that the unsaturated fatty acids present in the frying oil promoted PAH production. 

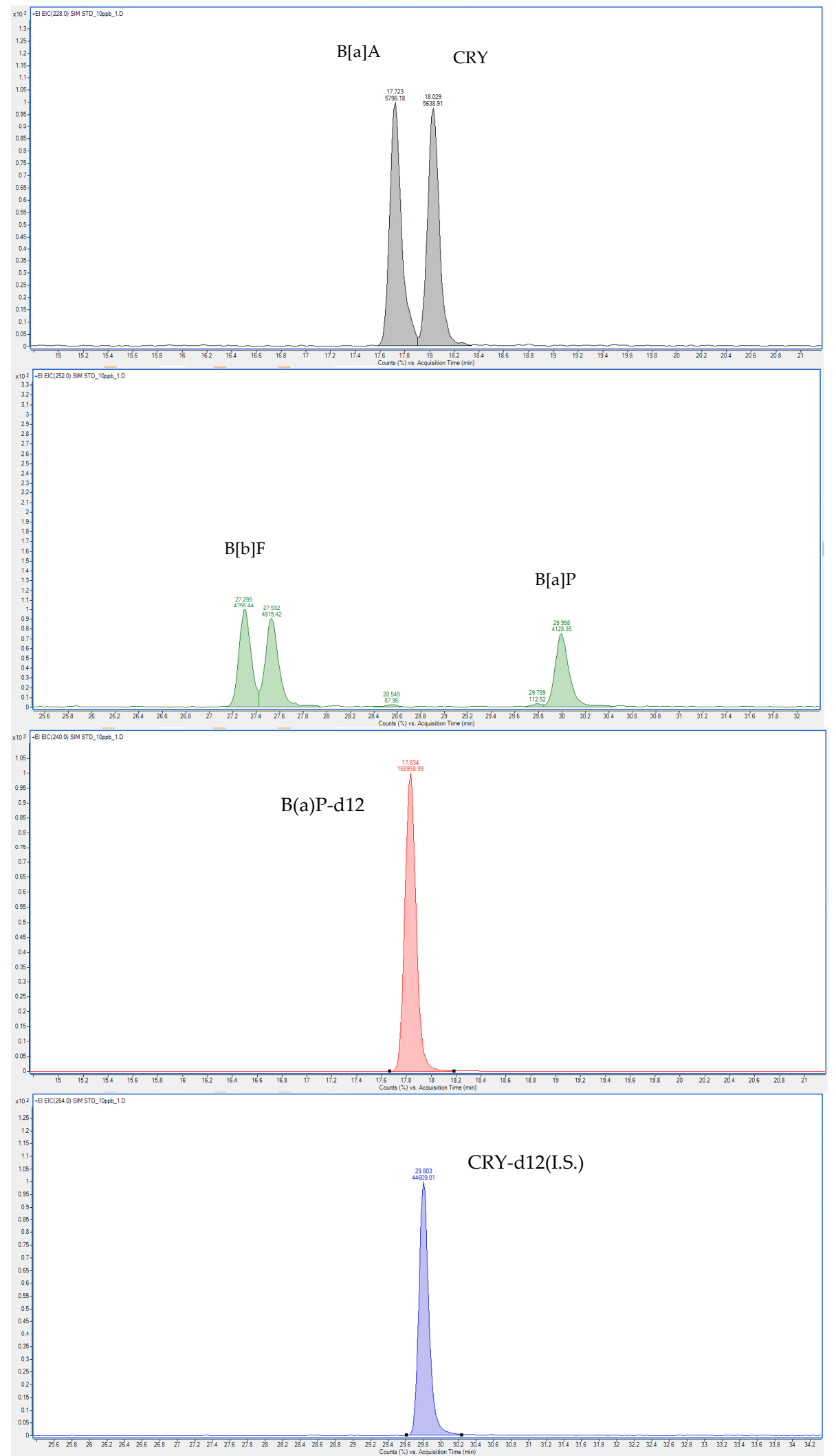

Figure 2. Gas chromatography-mass spectrometry (GC-MS) total ion chromatograms of a mixture of the four polycyclic aromatic hydrocarbons (PAHs) $(10 \mu \mathrm{g} / \mathrm{kg})$ and the B(a)P-d12 and CRY-d12 internal standards $(10 \mu \mathrm{g} / \mathrm{kg})$. Benzo(a)anthracene, B(a)A; benzo(b)fluoranthene, B(b)F; chrysene, CRY; benzo(a)pyrene, B(a)P; benzo(a)pyrene-d12, B(a)P-d12; and chrysene-d12, CRY-d12. 
Table 4. Levels ${ }^{1}(\mu \mathrm{g} / \mathrm{kg})$ of the four PAHs in the air-fried and deep-fat-fried chicken breast, thigh, and wing samples thawed in a microwave, in a refrigerator, or by water immersion.

\begin{tabular}{|c|c|c|c|c|c|c|c|}
\hline Frying Method & Thawing Method & Chicken Part & B(a)A & $B(b) F$ & CRY & $\mathbf{B}(\mathbf{a}) \mathbf{P}$ & $\mathrm{PAH}^{2}$ \\
\hline \multirow{9}{*}{ Air frying } & \multirow{3}{*}{ Microwave } & Breasts & $0.27 \pm 0.03^{\mathrm{BXb}}$ & $0.28 \pm 0.05^{\mathrm{AXa}}$ & $0.94 \pm 0.12^{\mathrm{BXb}}$ & $0.52 \pm 0.03^{\mathrm{AXa}}$ & $2.00 \pm 0.20^{\mathrm{BXb}}$ \\
\hline & & Thighs & $0.31 \pm 0.02^{\mathrm{AXb}}$ & $0.24 \pm 0.05^{\mathrm{AXa}}$ & $1.06 \pm 0.01^{\mathrm{BYb}}$ & $0.54 \pm 0.00^{\mathrm{BXa}}$ & $2.15 \pm 0.07^{\mathrm{BXYb}}$ \\
\hline & & Wings & $0.43 \pm 0.04^{\mathrm{AXa}}$ & $0.30 \pm 0.05^{\mathrm{BXa}}$ & $1.43 \pm 0.10^{\mathrm{AXa}}$ & $0.55 \pm 0.05^{\mathrm{AXa}}$ & $2.71 \pm 0.18^{\mathrm{BXa}}$ \\
\hline & \multirow{3}{*}{ Refrigerator } & Breasts & $0.26 \pm 0.04^{\mathrm{AXa}}$ & $0.19 \pm 0.02^{\mathrm{BYb}}$ & $0.95 \pm 0.05^{\mathrm{AXb}}$ & $0.56 \pm 0.08^{\mathrm{AXa}}$ & $1.96 \pm 0.16^{\mathrm{BXb}}$ \\
\hline & & Thighs & $0.33 \pm 0.03^{\mathrm{AXa}}$ & $0.20 \pm 0.02^{\mathrm{BXb}}$ & $1.01 \pm 0.05^{\mathrm{BYb}}$ & $0.55 \pm 0.02^{\mathrm{BXa}}$ & $2.08 \pm 0.07^{\mathrm{BYb}}$ \\
\hline & & Wings & $0.32 \pm 0.04^{\mathrm{AYa}}$ & $0.35 \pm 0.05^{\mathrm{AXa}}$ & $1.30 \pm 0.08^{\mathrm{AXa}}$ & $0.54 \pm 0.09^{\mathrm{AXa}}$ & $2.51 \pm 0.18^{\mathrm{BXa}}$ \\
\hline & \multirow{3}{*}{ Water immersion } & Breasts & $0.29 \pm 0.02^{\mathrm{BXab}}$ & $0.25 \pm 0.04^{\mathrm{AXYa}}$ & $1.04 \pm 0.08^{\mathrm{BXa}}$ & $0.51 \pm 0.00^{\mathrm{BXa}}$ & $2.08 \pm 0.10^{\mathrm{BXa}}$ \\
\hline & & Thighs & $0.24 \pm 0.04^{\mathrm{BYb}}$ & $0.22 \pm 0.03^{\mathrm{AXa}}$ & $1.22 \pm 0.09^{\mathrm{AXa}}$ & $0.59 \pm 0.05^{\mathrm{BXa}}$ & $2.26 \pm 0.09^{\mathrm{BXa}}$ \\
\hline & & Wings & $0.32 \pm 0.02^{\mathrm{BYa}}$ & $0.30 \pm 0.06^{\mathrm{AXa}}$ & $1.10 \pm 0.11^{\mathrm{BYa}}$ & $0.59 \pm 0.09^{\mathrm{AXa}}$ & $2.31 \pm 0.24^{\mathrm{BXa}}$ \\
\hline \multirow{9}{*}{ Deep-fat frying } & \multirow{3}{*}{ Microwave } & Breasts & $0.42 \pm 0.05^{\mathrm{AXa}}$ & $0.33 \pm 0.07^{\mathrm{AXYab}}$ & $1.30 \pm 0.09^{\mathrm{AXb}}$ & $0.59 \pm 0.07^{\mathrm{AYa}}$ & $2.64 \pm 0.14^{\mathrm{AXb}}$ \\
\hline & & Thighs & $0.39 \pm 0.07^{\mathrm{AXa}}$ & $0.31 \pm 0.06^{\mathrm{AXb}}$ & $1.44 \pm 0.14^{\mathrm{AXab}}$ & $0.76 \pm 0.04^{\mathrm{AXYa}}$ & $2.90 \pm 0.2 \mathrm{~A}^{\mathrm{Xab}}$ \\
\hline & & Wings & $0.46 \pm 0.06^{\mathrm{AXa}}$ & $0.42 \pm 0.04^{\mathrm{AXa}}$ & $1.52 \pm 0.06^{\mathrm{AXa}}$ & $0.76 \pm 0.13^{\mathrm{AXa}}$ & $3.17 \pm 0.15^{\mathrm{AXa}}$ \\
\hline & \multirow{3}{*}{ Refrigerator } & Breasts & $0.35 \pm 0.06^{\mathrm{AXa}}$ & $0.40 \pm 0.07^{\mathrm{AXa}}$ & $1.21 \pm 0.24^{\mathrm{AXa}}$ & $0.64 \pm 0.02^{\mathrm{AYa}}$ & $2.60 \pm 0.21^{\mathrm{AXa}}$ \\
\hline & & Thighs & $0.40 \pm 0.03^{\mathrm{AXa}}$ & $0.35 \pm 0.03^{\mathrm{AXa}}$ & $1.40 \pm 0.09^{\mathrm{AXa}}$ & $0.64 \pm 0.02^{\mathrm{AYa}}$ & $2.79 \pm 0.09^{\mathrm{AXa}}$ \\
\hline & & Wings & $0.40 \pm 0.03^{\mathrm{AXa}}$ & $0.45 \pm 0.06^{\mathrm{AXa}}$ & $1.40 \pm 0.09^{\mathrm{AXa}}$ & $0.59 \pm 0.01 \mathrm{AXb}$ & $2.84 \pm 0.09^{\mathrm{AYa}}$ \\
\hline & \multirow{3}{*}{ Water immersion } & Breasts & $0.43 \pm 0.05^{\mathrm{AXa}}$ & $0.27 \pm 0.02^{\mathrm{AYb}}$ & $1.33 \pm 0.05^{\mathrm{AXa}}$ & $0.79 \pm 0.03^{\mathrm{AXa}}$ & $2.81 \pm 0.13^{\mathrm{AXa}}$ \\
\hline & & Thighs & $0.40 \pm 0.03^{\mathrm{AXa}}$ & $0.27 \pm 0.04^{\mathrm{AXb}}$ & $1.33 \pm 0.01^{\mathrm{AXa}}$ & $0.78 \pm 0.10^{\mathrm{AXa}}$ & $2.78 \pm 0.08^{\mathrm{AXa}}$ \\
\hline & & Wings & $0.46 \pm 0.03^{\mathrm{AXa}}$ & $0.36 \pm 0.03^{\mathrm{AXa}}$ & $1.38 \pm 0.07^{\mathrm{AXa}}$ & $0.73 \pm 0.09^{\mathrm{AXa}}$ & $2.93 \pm 0.14^{\mathrm{AXYa}}$ \\
\hline
\end{tabular}

${ }^{1}$ : Each value represents the average of three independent repetitions \pm standard deviation. ${ }^{2}$ : $\mathrm{PAH} 4$ is the sum of the benzo(a)anthracene $(\mathrm{B}(\mathrm{a}) \mathrm{A})$, benzo(b)fluoranthene $(\mathrm{B}(\mathrm{b}) \mathrm{F})$, chrysene $(\mathrm{CRY})$, and benzo(a)pyrene $(\mathrm{B}(\mathrm{a}) \mathrm{P})$ contents. $\mathrm{A}, \mathrm{B}$ indicate statistically significant differences $(p<0.05)$ between the PAH levels of the same thawing methods and the same chicken meat parts where the frying method was varied. ${ }^{X}, Y$ indicate statistically significant differences $(p<0.05)$ among the PAH levels of the same chicken meat parts and the same frying methods where the thawing method was varied. ${ }^{a}, b$ indicate statistically significant differences $(p<0.05)$ among the PAH levels of the chicken meat parts where the same frying methods and same thawing methods were used. 


\subsection{Effect of Thawing Method on PAH Formation}

The effect of the thawing method (i.e., microwave, refrigerator, or water immersion) on the formation of PAHs was investigated using the same frying method and same chicken meat parts. It was found that the thawing method had no significant effect $(p>0.05)$ on PAH formation in air-fried chicken meats, with the exception of the thigh meat thawed in a refrigerator. In the case of the deep-fat-fried samples, the total PAH levels in the chicken wings thawed in a refrigerator were significantly lower $(p<0.05)$ than those of the chicken wings thawed using either a microwave or water immersion.

Previous research confirmed that thawing in a refrigerator resulted in a lower drip loss of $0.62 \%$ among chicken breast samples [43]. Additionally, the presence of water is an important factor in PAH formation because it prevents incomplete combustion by providing oxygen during heating [44,45]. Therefore, it is likely that the lower quantities of PAHs formed in the chicken samples thawed using a refrigerator were due to reduced moisture loss.

\subsection{PAH Formation in Different Chicken Meat Parts}

The formation of PAHs was examined in the chicken breast, thigh, and wing samples that were thawed and fried using the same methods. Specifically, the air-fried chicken wings exhibited the highest PAH contents, followed by the chicken thigh and breast samples. The total PAH levels were in the range of $1.96-2.08 \mu \mathrm{g} / \mathrm{kg}$ for the chicken breasts, $2.08-2.26 \mu \mathrm{g} / \mathrm{kg}$ for the chicken thighs, and $2.31-2.71 \mu \mathrm{g} / \mathrm{kg}$ for the chicken wings. Similar trends were observed for the deep-fat-fried chicken samples. However, no significant differences $(p>0.05)$ were observed among the deep-fat-fried chicken meat samples, with the exception of the chicken breast thawed in the microwave. Lee et al. [33] reported average PAH contents of $0.60-0.76 \mu \mathrm{g} / \mathrm{kg}$ for chicken breasts, $0.94-1.14 \mu \mathrm{g} / \mathrm{kg}$ for chicken thighs, and $0.70-1.17 \mu \mathrm{g} / \mathrm{kg}$ for chicken wings. According to Koh and Yu [46], the lipid contents of chicken wings (14.9\%) are higher than those of thighs $(2.8 \%)$ and breasts $(1.2 \%)$. Additionally, the most prevalent fatty acid is oleic acid $(42.57 \%)$, followed by palmitic acid $(27.5 \%)$ and linoleic acid $(15.96 \%)$ in chicken meats. Additionally, it has been reported that the fat content of a sample is an important factor in determining the extent of PAH formation in grilled meat [47]. More specifically, PAH formation can occur upon the pyrolysis of organic matter, and the greatest concentrations of PAHs have been shown to arise from the pyrolysis of fat [48], which accounts for the higher levels of PAH formation observed in the chicken wing samples. The regulatory maximum level for $\mathrm{B}(\mathrm{a}) \mathrm{P}$ in smoked meat products is $2 \mu \mathrm{g} / \mathrm{kg}$, whereas the maximum PAH4 level is $12 \mu \mathrm{g} / \mathrm{kg}$ [21]. In the present study, none of the chicken samples exceeded these maximum values; the B(a)P contents were $0.51-0.79 \mu \mathrm{g} / \mathrm{kg}$ for the chicken breast samples, $0.54-0.78 \mu \mathrm{g} / \mathrm{kg}$ for the chicken thigh samples, and $0.54-0.76 \mu \mathrm{g} / \mathrm{kg}$ for the chicken wing samples. Interestingly, these values were significantly lower than the level of $9.2 \mu \mathrm{g} / \mathrm{kg}$ in duck meat reported by Chen and Lin [49]. However, the B(a)P and PAH4 levels (max 0.79 and $3.17 \mu \mathrm{g} / \mathrm{kg}$, respectively) were similar to previously reported levels for beef ( 0.59 and $4.32 \mu \mathrm{g} / \mathrm{kg}$, respectively) [50]. Furthermore, the maximum B(a)P level fell within the range of n.d. $-1.2 \mu \mathrm{g} / \mathrm{kg}$ previously reported for deep-fat-fried chicken breasts [51].

\section{Conclusions}

We herein reported our investigation into the effects of different frying methods (air frying and deep-fat frying) and thawing methods (microwave, refrigerator, and water immersion) of chicken meat parts (breasts, thighs, and wings) on the formation of acrylamide and PAHs. The air-fried samples exhibited lower acrylamide and total PAH contents than the deep-fat-fried samples due to the lower oil content used during the frying process. No significant differences were observed among the thawing methods and the chicken parts in terms of the acrylamide content. However, higher PAH contents were detected in the chicken wing samples in comparison with the chicken thigh and chicken breast samples, likely due to the higher fat content of the chicken wings. Additionally, the amounts of carcinogenic compounds detected in this study were lower than those reported in previous studies because no 
batter was employed, and the frying oil was relatively fresh. Overall, air frying reduced the formation of acrylamide and PAHs in comparison with deep-fat frying. Therefore, these results may be useful in determining the optimal frying method for chicken in terms of minimizing the formation of potentially hazardous substances.

Author Contributions: Conceptualization, J.-W.H.; methodology, M.-S.C., M.J., and K.-W.L.; investigation, J.-S.L. and J.-W.H.; writing-Original draft preparation, M.-S.C., J.-S.L., and J.-W.H.; writing-Review and editing, M.-S.C., M.J., and K.-W.L. All authors have read and agreed to the published version of the manuscript.

Funding: This research was supported by a grant (18162 MFDS 053) from Ministry of Food and Drug Safety in 2019 .

Acknowledgments: This research was supported by the Chung-Ang University Graduate Research Scholarship in 2018 .

Conflicts of Interest: The authors declare no conflict of interest.

\section{References}

1. Animal Husbandry and Nutrition. Available online: https://www.intechopen.com/books/animal-husband ry-and-nutrition/quality-of-chicken-meat (accessed on 15 April 2020).

2. Korean Fair Trade Commission. 2019. Available online: http://www.ftc.go.kr/www/selectReportUserView.d o? $\mathrm{key}=10 \&$ rpttype $=1$ \&report_data_no $=8091$ (accessed on 23 November 2019).

3. Ministry of Agriculture Food and Rural Affairs. Available online: http://kass.mafra.go.kr/kass/phone/kass.h tm (accessed on 25 November 2019).

4. The National Chicken Council. Per Capita Consumption of Poultry and Livestock, 1960 to Forecast 2020, in Pounds. Available online: https://www.nationalchickencouncil.org/about-the-industry/statistics/per-cap ita-consumption-of-poultry-and-livestock-1965-to-estimated-2012-in-pounds/ (accessed on 14 April 2020).

5. USDA/FAS PSD Online. Available online: https://fas.usda.gov/psdonline/psdQuery.aspx (accessed on 15 April 2020).

6. Lee, J.-K.; Yoon, K.-S. A study of adult's consumption of cooked food with high heat. J. Korean Soc. Food Sci. Nutr. 2011, 40, 290-307. [CrossRef]

7. Aladedunye, F.A.; Przybylski, R. Degradation and nutritional quality changes of oil during frying. J. Am. Oil Chem. Soc. 2009, 86, 149-156. [CrossRef]

8. Foegeding, E.A.; Davis, J.P. Food protein functionality: A comprehensive approach. Food Hydrocoll. 2011, 25, 1853-1864. [CrossRef]

9. Gertz, C. Fundamentals of the frying process. Eur. J. Lipid Sci. Technol. 2014, 116, 669-674. [CrossRef]

10. Sengar, G.; Sharma, H.K. Food caramels: A review. J. Food Sci. Technol. 2014, 51, 1686-1696. [CrossRef] [PubMed]

11. Ibrahim, R.M.; Nawar, I.; Yousef, M.I.; El-Sayed, M.I.; Hassanein, A. Protective Role of Natural Antioxidants Against the Formation and Harmful Effects of Acrylamide in Food. Trends Appl. Sci. Res. 2019, 14, 41-55. [CrossRef]

12. Zhang, Q.; Saleh, A.S.; Chen, J.; Shen, Q. Chemical alterations taken place during deep-fat frying based on certain reaction products: A review. Chem. Phys. Lipids 2012, 165, 662-681. [CrossRef]

13. Rose, M.; Holland, J.; Dowding, A.; Petch, S.R.; White, S.; Fernandes, A.; Mortimer, D. Investigation into the formation of PAHs in foods prepared in the home to determine the effects of frying, grilling, barbecuing, toasting and roasting. Food Chem. Toxicol. 2015, 78, 1-9. [CrossRef]

14. Demirok, E.; Kolsaric1, N. Effect of green tea extract and microwave pre-cooking on the formation of acrylamide in fried chicken drumsticks and chicken wings. Food Res. Int. 2014, 63, 290-298. [CrossRef]

15. Carrabs, G.; Marrone, R.; Mercogliano, R.; Carosielli, L.; Vollano, L.; Anastasio, A. Polycyclic aromatic hydrocarbons residues in Gentile di maiale, a smoked meat product typical of some mountain areas in Latina province (Central Italy). Ital. J. Food Saf. 2014, 3, 102-104. [CrossRef]

16. International Agency for Research on Cancer (IARC). Some industrial chemicals. In IARC Monographs on the Evaluation of Carcinogenesis Risks to Humans; IARC: Lyon, France, 1994; Volume 60, pp. 435-453. 
17. International Agency for Research on Cancer (IARC). Polynuclear aromatic compounds, part 1, chemical, environmental, and experimental data. In IARC Monographs on the Evaluation of Carcinogenesis Risks to Humans; IARC: Lyon, France, 1983; Volume 32, pp. 33-451.

18. Teruel, M.D.R.; Gordon, M.; Linares, M.B.; Garrido, M.D.; Ahromrit, A.; Niranjan, K. A comparative study of the characteristics of french fries produced by deep fat frying and air frying. J. Food Sci. 2015, 80, E349-E358. [CrossRef] [PubMed]

19. European Commission (EC). European Commission Regulation (EC) No 1881/2006 of 19 December 2006 Setting Maximum Levels for Certain Contaminants in Foodstuffs (Text with EEA relevance). OJEU 2006, 364, 5-24.

20. European Food Safety Authority. EFSA Scientific Opinion of the Panel on Contaminants in the food chain on a request from the European Commission on polycyclic aromatic hydrocarbons in food. EFSA J. 2008, 724, 1-114.

21. Commission Regulation (EU). Available online: https://op.europa.eu/en/publication-detail/-/publication/6a 58ffa2-7404-4acf-b1df-298f611f813d/language-en (accessed on 15 April 2020).

22. Basuny, A.M.; Arafat, S.M.; Ahmed, A.A. Vacuum frying: An alternative to obtain high quality potato chips and fried oil. Banats J. Biotechnol. 2012, 3, 22-30.

23. Andrés-Bello, A.; García-Segovia, P.; Martínez-Monzó, J. Vacuum frying: An alternative to obtain high-quality dried products. Food Eng. Rev. 2011, 3, 63-78. [CrossRef]

24. Andrés, A.; Arguelles, Á.; Castelló, M.L.; Heredia, A. Mass transfer and volume changes in French fries during air frying. Food Bioproc. Technol. 2013, 6, 1917-1924. [CrossRef]

25. Tuta, S.; Palazoğlu, T.K.; Gökmen, V. Effect of microwave pre-thawing of frozen potato strips on acrylamide level and quality of French fries. J. Food Eng. 2010, 97, 261-266. [CrossRef]

26. Dueik, V.; Moreno, M.C.; Bouchon, P. Microstructural approach to understand oil absorption during vacuum and atmospheric frying. J. Food Eng. 2012, 111, 528-536. [CrossRef]

27. Cruz, G.; Cruz-Tirado, J.; Delgado, K.; Guzman, Y.; Castro, F.; Rojas, M.L.; Linares, G. Impact of pre-drying and frying time on physical properties and sensorial acceptability of fried potato chips. Food Sci. Technol. 2018, 55, 138-144. [CrossRef]

28. Sansano, M.; Juan-Borrás, M.; Escriche, I.; Andrés, A.; Heredia, A. Effect of pretreatments and air-frying, a novel technology, on acrylamide generation in fried potatoes. J. Food Sci. 2015, 80, T1120-T1128. [CrossRef]

29. Chosunbiz. Available online: https://biz.chosun.com/site/data/html_dir/2019/02/21/2019022100937.html (accessed on 25 November 2019).

30. The Ministry of Food and Drug Safety. Available online: http://www.prism.go.kr/homepage/origin/ retrieveOriginDetail.do;jsessionid=259A3D50EBB62ADE8CC47A32B02495C6.node02?.cond_research_ name=\&cond_research_start_date=\&cond_research_end_date=\&cond_organ_id=1471000\&research_id $=1470000-200700053 \&$ pageIndex=24\&leftMenuLevel=120 (accessed on 20 November 2019).

31. United States Department of Agriculture. The Big Thaw-Safe Defrosting Methods for Consumers. Available online: https://www.fsis.usda.gov/wps/portal/fsis/topics/food-safety-education/get-answers/food-s afety-fact-sheets/safe-food-handling/the-big-thaw-safe-defrosting-methods-for-consumers/ct_index/!ut/p/ a1/jZFRT8IwFIV_zR5LO4dk-LYsMYCySYgy9kLKdtc22VrSXpz66y3zCQNK-9R7zpd77yktaUFLzd-V4KiM 5u3pXU52bMUm4TRli3waPrJ59rbKn9KUxet7b9j-YciiG_krJ2H_8YsbGtzZZboUtDxwlETpxtBCABKuXQ _W0aIxpiaON4CfpOEVEicB0AunGhlUyXXdKilogRLIXgmCkvcDRGporHHoVdIBSIM7z1hSGe2O3dCg wp3SNXzQDS3P52Whv_MsWo9niyxi-fi34UKgP4briflIRGv2w-9tE72PYr-7hQYs2NHR-rJEPLiHgAWs7_ uRMEa0MKpMF7BLiPTL0eLcSQ_da_H1nMyYeuk2sUu-AT1hIAs!/\#1 (accessed on 25 November 2019).

32. The Ministry of Food and Drug Safety. Available online: http://www.law.go.kr/LSW/admRulInfoP.do?adm RulSeq=2000000012210 (accessed on 20 November 2019).

33. Lee, Y.-N.; Lee, S.; Kim, J.-S.; Patra, J.K.; Shin, H.-S. Chemical analysis techniques and investigation of polycyclic aromatic hydrocarbons in fruit, vegetables and meats and their products. Food Chem. 2019, 277, 156-161. [CrossRef] [PubMed]

34. Umano, K.; Shibamoto, T. Analysis of acrolein from heated cooking oils and beef fat. J. Agric. Food Chem. 1987, 35, 909-912. [CrossRef]

35. Yasahura, A.; Tanaka, Y.; Hengel, M.; Shibamoto, T. Gas chromatographic investigation of acrylamide formation in browning model system. J. Agric. Food Chem. 2003, 51, 3999-4003. [CrossRef] [PubMed] 
36. Tareke, E. Identification and Origin of Potential Background Carcinogens: Endogenous Isoprene and Oxiranes, Dietary Acrylamide. Ph.D. Thesis, Stockholm University, Stockholm, Sweden, 2003.

37. Belgin Erdoğdu, S.; Palazoğlu, T.K.; Gökmen, V.; Şenyuva, H.Z.; Ekiz, H.İ. Reduction of acrylamide formation in French fries by microwave pre-cooking of potato strips. J. Sci. Food Agric. 2007, 87, 133-137. [CrossRef]

38. Commission Recommendation (EC). Investigations into the levels of acrylamide in food. OJEU 2013, 50, L301/15.

39. Chen, B.H.; Chen, Y.C. Formation of polycyclic aromatic hydrocarbons in the smoke from heated model lipids and food lipids. J. Agric. Food Chem. 2001, 49, 5238-5243. [CrossRef]

40. Cossignani, L.; Giua, L.; Simonetti, M.S.; Blasi, F. Volatile compounds as indicators of conjugated and unconjugated linoleic acid thermal oxidation. Eur. J. Lipid Sci. Technol. 2014, 116, 407-412. [CrossRef]

41. Ezechi, E.H.; Affam, A.C.; Muda, K. Handbook of Research on Resource Management for Pollution and Waste Treatment, 1st ed.; IGI Global: Hershey, PA, USA, 2019; p. 29.

42. Kostik, V.; Memeti, S.; Bauer, B. Fatty acid composition of edible oils and fats. J. Hyg. Eng. Des. 2013, 4, 112-116.

43. Benli, H. Consumer attitudes toward storing and thawing chicken and effects of the common thawing practices on some quality characteristics of frozen chicken. Asian-Australas. J. Anim. Sci. 2016, 29, 100-108. [CrossRef]

44. Olatunji, O.S.; Fatoki, O.S.; Opeolu, B.O.; Ximba, B.J. Determination of polycyclic aromatic hydrocarbons [PAHs] in processed meat products using gas chromatography-Flame ionization detector. Food Chem. 2014, 156, 296-300. [CrossRef]

45. Min, S.; Patra, J.K.; Shin, H.-S. Factors influencing inhibition of eight polycyclic aromatic hydrocarbons in heated meat model system. Food Chem. 2018, 239, 993-1000. [CrossRef] [PubMed]

46. Koh, H.-Y.; Yu, I.-J. Nutritional analysis of chicken parts. J. Korean Soc. Food Sci. Nutr. 2015, 44, $1028-1034$. [CrossRef]

47. Fretheim, K. Polycyclic aromatic hydrocarbons in grilled meat products-A review. Food Chem. 1983, 10, 129-139. [CrossRef]

48. Bartle, K.D. Analysis and occurrence of PAHs in food. In Food Contaminants: Sources and Surveillance, 1st ed.; Creaser, C., Purchase, R., Eds.; Royal Society of Chemistry: Cambridge, UK, 1991; pp. 41-60.

49. Chen, B.; Lin, Y. Formation of polycyclic aromatic hydrocarbons during processing of duck meat. J. Agric. Food Chem. 1997, 45, 1394-1403. [CrossRef]

50. Bogdanović, T.; Pleadin, J.; Petričević, S.; Listeš, E.; Sokolić, D.; Marković, K.; Ozogul, F.; Šimat, V. The occurrence of polycyclic aromatic hydrocarbons in fish and meat products of Croatia and dietary exposure. J. Food Compost. Anal. 2019, 75, 49-60. [CrossRef]

51. Aaslyng, M.D.; Duedahl-Olesen, L.; Jensen, K.; Meinert, L. Content of heterocyclic amines and polycyclic aromatic hydrocarbons in pork, beef and chicken barbecued at home by Danish consumers. Meat. Sci. 2013, 93, 85-91. [CrossRef]

(C) 2020 by the authors. Licensee MDPI, Basel, Switzerland. This article is an open access article distributed under the terms and conditions of the Creative Commons Attribution (CC BY) license (http://creativecommons.org/licenses/by/4.0/). 